\title{
STUDY OF AIR TERMINALS SHIELDING DUE TO LIGHTNING LEADER SLANT
}

\author{
M. Nayel \\ Assiut University, Egypt \\ E-mail: mnayel@aun.edu.eg
}

(Received September 13, 2008 Accepted January 15, 2009)

This paper studies the effect of the lightning leader slant on the shielding angle of the air terminal. The lightning leader is modeled by using discrete line charges. The Rizk voltage condition is assumed as the upward lightning leader condition which is the lightning stroke condition to the lightning rod. The attractive radius and the shielding angle of the air terminal are calculated for different air terminal heights, different lightning currents and different lightning leader slopes. The calculated results show that the attractive radius of air terminal depends on the rod height, the lightning current and the lightning leader slope. A formula related between the lightning current, the lightning leader slope, the attractive radius and the air terminal height is proposed. The slant of lightning leader decreases the air terminal shielding angle, especially at low lightning current and long air terminal.

KEYWORDS- Lightning, Air Terminal, Attractive Radius, Shielding Angle, Shielding Failure.

\section{INTRODUCTION}

Lightning protection has been practiced for almost 250 years. The main component of the lightning protection system is the conventional air terminal (Franklin rod). The air terminal is still in use throughout the world and it has been scientifically validated. The air terminal serves as a sacrificial device when the lightning strikes it rather than the building. In a typical building, several of these lightning rods are installed at various locations on the roof that are likely to be struck by lightning. In this way, the lightning will have a high probability of striking the lightning rods instead of the roof. Therefore, the building is considered protected from direct lightning strikes. The other components of the lightning protection system are the down conductor and the ground terminal [1]. We still lack an exact expression of the protective effect produced by the air termination. Recent studies show that there are many cases where the lightning damage location (or stricken point) occurred very close to early streamer emission ESE or air terminal. They show that the presence of several ESE's or air terminals either on the same building or on adjacent buildings, still resulted in lightning strikes on one or more of these building [2-3].

The slant lightning leader is an important reason for the shielding failure. Fig. 1.a shows the photo of the direct lightning stroke of slant leader to the lower phase conductor of the Minami-Iwaki main transmission line [4]. The slant lightning leader is the main reason for bypassing the shielding wires and the upper phase 
conductors and strikes the lower phase conductor. Fig.1 b shows the photo of the slant lightning leader[5].

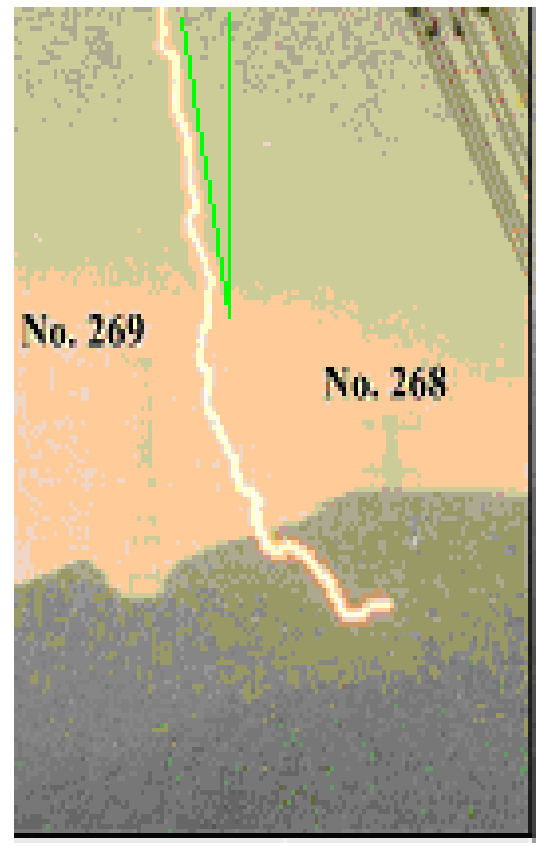

(a)

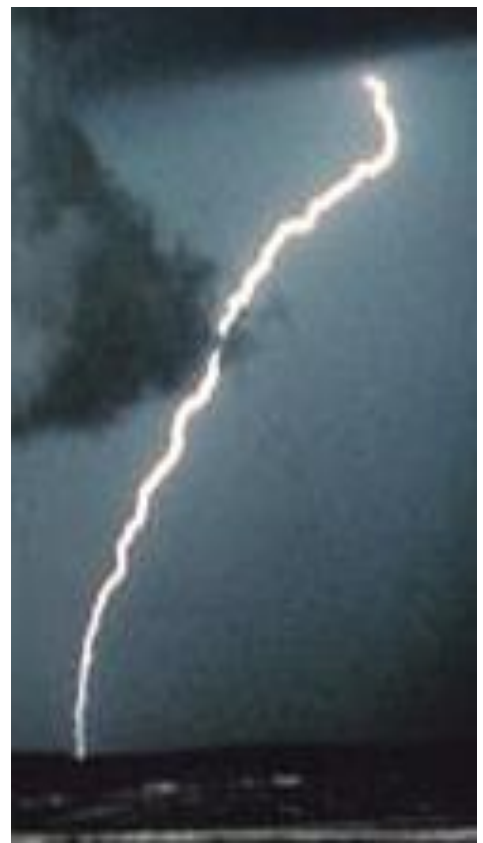

(b)

Fig. 1: (a) Photos of direct lightning strokes (slant lightning leader) on the Minami Iwaki line between No. 267 and No. 268[4]. (b) Photos of slant lightning leader[5]

The electrogeometric model (EGM) is a technique used for estimating the protection zone of air terminal [6-12]. The EGM was first introduced by Whitehead in the late 1960s [6] and is based on field studies of natural lightning. It links two important parameters of the lightning stroke to an earthed structure, namely the prospective peak stroke current, $\left(\mathrm{I}_{\mathrm{p}}\right)$, and the striking distance, $\left(\mathrm{d}_{\mathrm{s}}\right)$. Based on the observations of the lightning strokes to different transmission lines at different conditions, Eriksson had proposed an attractive radius equation with a dependence on the air terminal height $(\mathrm{h})[12]$ :

$$
\mathbf{R}_{\mathbf{a} \text { Eriksson }}=0.84 \mathbf{I}^{0.76} \mathbf{h}^{0.6} \text {. }
$$

Rizk had also studied the effect of air terminal height on the attractive radius [13], for different currents and air terminal heights. His regression analysis showed that for a current of $31 \mathrm{kA}$ and height in the range $10-60 \mathrm{~m}$, are approximated by

$$
\mathbf{R}_{\text {a Rizk }}(31, \mathbf{h})=24.6 \mathbf{h}^{0.4} \text {. }
$$

In this paper, the studied problem is modeled based on Rizk condition to study the attractive radius formula of air terminal for vertical and horizontal conductor. The Shielding angle of air terminal is estimated for different lightning leader currents and slope with the ground. 


\section{STUdied MOdeL}

The air terminal of height $\mathrm{h}$ has been exposed to a downward lightning leader, as shown in Fig.2.

The charge distribution inside the downward lightning leader is very complicated. The charge density is the highest at the level of the lightning leader tip and decreases with the lightning leader height. Different charge distribution inside the lightning leader, such as an exponential decay of the charge density, a combination between point charge at the leader tip and constant line charge, and a combination between point charge at the leader tip and linear charge decay, were assumed in previous works and a comparison between these different charge distributions has been studied before [14] and showed that the exponential decay is more accurate.

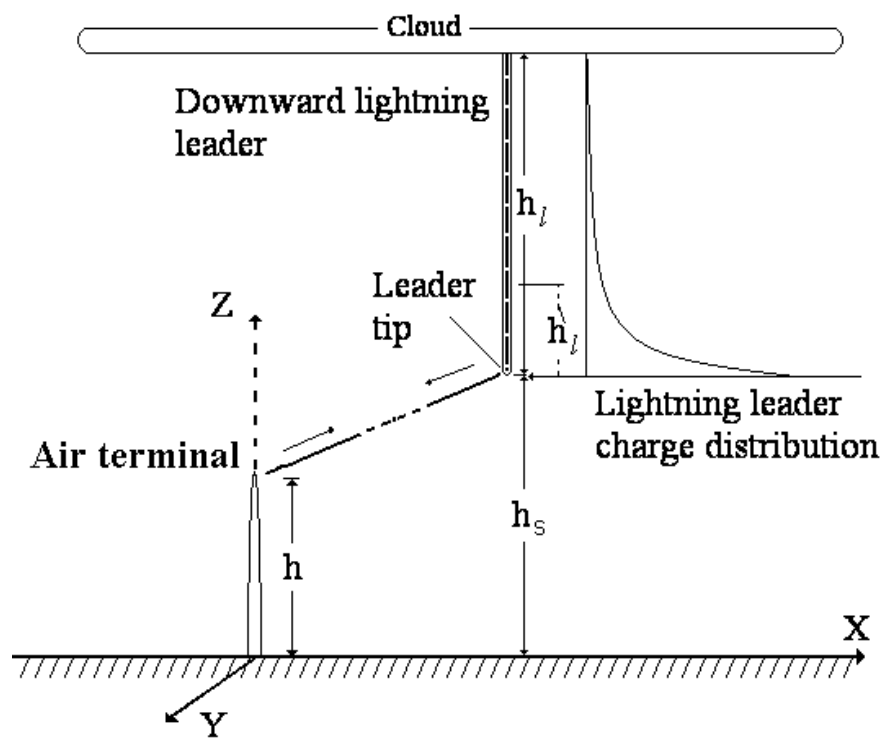

Fig. 2: Schematic arrangement of air terminal stroked by the downward lightning leader.

In this paper, the charge decaying distribution along the stepped leader is assumed to be exponential of negative charge and given by

$$
\rho\left(\mathbf{h}_{\mathbf{l}}^{\backslash}\right)=-\rho_{\mathbf{s}} \mathbf{e}^{-\alpha \mathbf{h}_{\mathbf{l}}^{\prime}}, \alpha=\frac{\ln \left(\rho_{\mathbf{c}} / \rho_{\mathbf{s}}\right)}{\left(\mathbf{h}_{\ell}\right)},
$$

where $\rho_{\mathrm{s}}$ is the line charge density in $\mathrm{C} / \mathrm{m}$ at the downward leader tip $\left(\mathrm{z}=\mathrm{h}_{\mathrm{s}}\right), \rho_{\mathrm{c}}$ is the line charge density in $\mathrm{C} / \mathrm{m}$ at the cloud base $\left(\mathrm{z}=\mathrm{h}_{\mathrm{c}}=\mathrm{h}_{\mathrm{s}}+\mathrm{h}_{\mathrm{l}}\right)$, and $\mathrm{h}_{\mathrm{l}}$ is the downward lightning leader length in $\mathrm{m}$.

For the most studied cases, the downward lightning leader length $h_{1}$ is assumed to be constant and equal to $3 \mathrm{~km}$ and $\rho c / \rho s=0.05$. This value results in $\alpha=10^{-3} \mathrm{~m}^{-1}$. The return stroke current speed is assumed to be 0.3 times the light speed [15]. The downward lightning leader is simulated by $\mathbf{N}_{\ell}$ discrete line charges along the positive $\mathrm{X}, \mathrm{Y}, \mathrm{Z}$ directions. The charge density for the $\mathbf{n}_{\ell}$ segment will be as follows: 


$$
\boldsymbol{\rho}_{\mathbf{n} \ell}=\frac{\boldsymbol{\rho}_{\mathbf{s}} \mathbf{e}^{\alpha \mathbf{h}_{\mathbf{s}}}}{-\boldsymbol{\alpha} \mathbf{h}_{\mathbf{l}} / \mathbf{N}_{\ell}}\left(\mathbf{e}^{-\boldsymbol{\alpha}\left(\mathbf{h}_{\mathbf{t}}+\mathbf{h}_{\mathbf{l}} \frac{\mathbf{n}_{\ell}-1}{\mathbf{N}_{\ell}}\right)}-\mathbf{e}^{-\boldsymbol{\alpha}\left(\mathbf{h}_{\mathbf{t}}+\mathbf{h}_{\mathbf{l}} \frac{\mathbf{n}_{\ell}}{\mathbf{N}_{\ell}}\right)}\right) .
$$

The potential of the downward lightning leader at any point in space is expressed as:

$$
\mathbf{V}_{\ell}=\sum_{\mathbf{n} \ell=1}^{\mathbf{N}_{\ell}} \boldsymbol{\rho}_{\mathbf{n} \ell}\left(\mathbf{P}_{\mathbf{n} \ell}-\mathbf{P}_{\mathbf{n} \ell}^{\backslash}\right),
$$

where $\mathbf{P}_{\mathbf{n} \ell}, \mathbf{P}_{\mathbf{n} \ell}^{\backslash}$ are the potential coefficients for $\mathrm{n}_{\ell}{ }^{\text {th }}$ discrete constant charge density and its image due to the ground effect (see Appendix I).

The formula proposed by Rizk [13] to estimate the voltage $\left(\mathrm{V}_{\mathrm{r}}\right)$ at the tip of air terminal at height (d) due to the presence of lightning leader is chosen to be the base of investigating the lightning stroke to the lightning rod.

$$
\mathbf{V}_{\mathbf{r}}=\frac{1556}{1+\frac{3.89}{\mathbf{d}}}
$$

\section{RESULtS AND Discussions}

\section{1 Attractive Radius}

By using the model described above, the attractive radius is obtained by calculating the voltage at air terminal tip at different lateral distance out from the lightning rod, tell this voltage reach Rizk voltage condition.

Figure 3 shows the effect of the vertical lightning leader current and the air terminal height on the attractive radius of the lightning rod. It shows that the attractive radius of the air terminal increases with the increase of the vertical lightning leader current and the air terminal height.

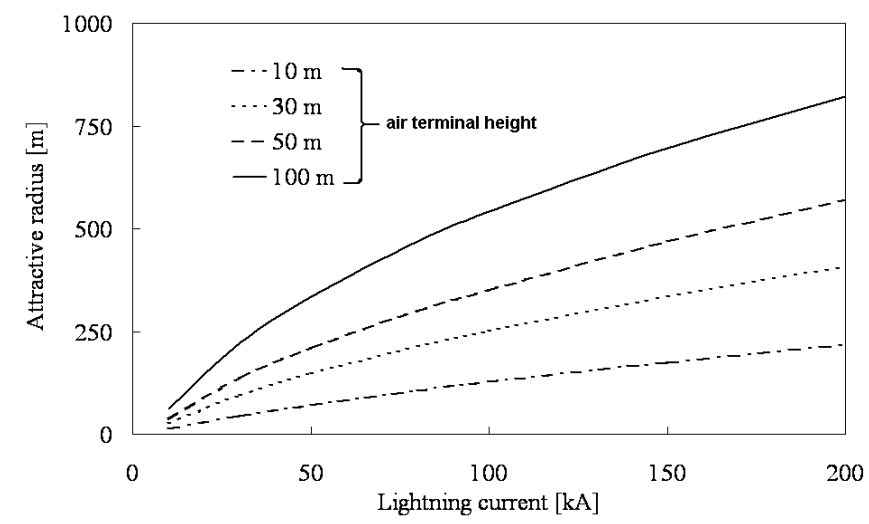

Fig. 3: Attractive radius of different vertical lightning current to the air terminal of different heights

For the current range of 10-200 kA and air terminal height range of $10-100$ $\mathrm{m}$, multiple regressions yielded the approximate expression [16]: 


$$
\mathbf{R}_{\mathrm{a}}=0.52 \mathbf{I}^{0.86} \mathbf{h}^{0.65} \text {. }
$$

Figure 4 shows the effect of lightning leader current and lightning leader slope on the attractive radius of the air terminal. It shows that, the attractive radius increases as the horizontal lightning leader current increases and as the lightning leader becomes vertical. The attractive radius of the air terminal due to the horizontal lightning leader is smaller than that due to the vertical lightning leader. This is due to the increase of the ground image effect of the lightning leader charge.

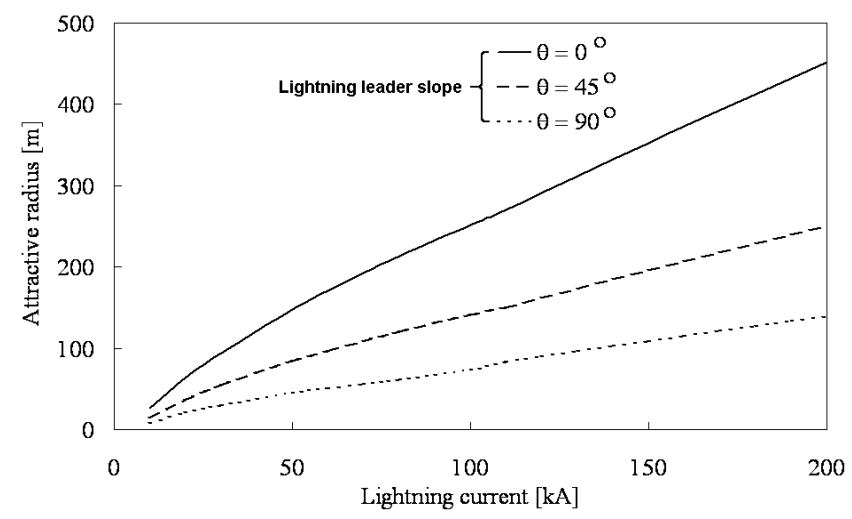

Fig. 4: Attractive radius of different lightning currents and slopes to the air terminal of height $10 \mathrm{~m}$.

For the current range of 10-200 kA, air terminal height range of $10-100 \mathrm{~m}$ and lightning leader current of slopes $\left(0^{\circ}, 22.5^{\circ}, 45^{\circ}\right.$ and $\left.90^{\circ}\right)$, multiple regressions yielded the approximate expression[16]:

$$
\mathbf{R}_{a}=0.52 \mathbf{I}^{0.7} \mathbf{h}^{0.86} \mathbf{e}^{-0.75 \theta}
$$

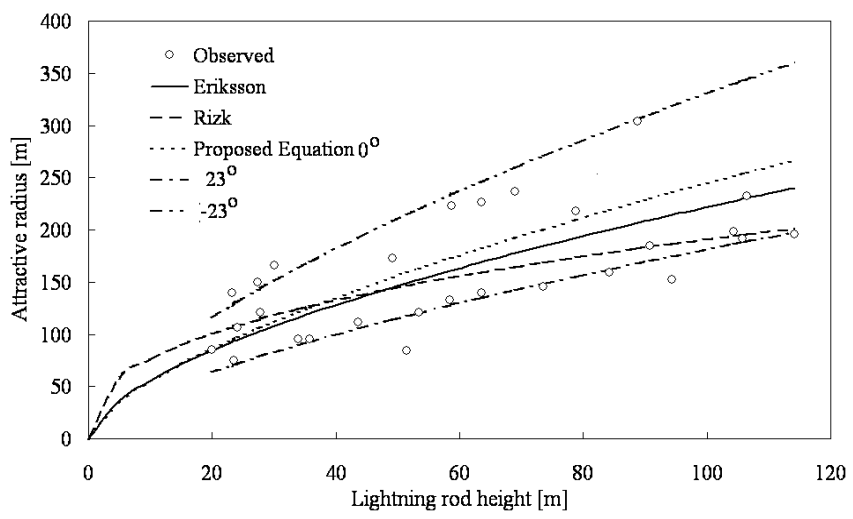

Fig. 5: Striking radius of, Rizk eq. (2), Eriksson eq. (1), observed results and the proposed eq. (8) for $0^{\circ}, 23^{\circ}-23^{\circ}$

Figure 5 shows the attractive radius of the proposed equation (8) for lightning slopes $\left(0^{\circ}, 23^{\circ},-23^{\circ}\right)$, Rizk (2) and Eriksson (1) equation compared to the observed results. It shows a good agreement of the proposed equation with Eriksson equation and observed results. The attractive radiuses for proposed equation (8) at slopes $23^{\circ}$ 
and $-23^{\circ}$ are more closed to the observed results, which means that the lightning leader for the observed results are often slant with $\pm 23^{\circ}$, if we consider the same conditions.

\section{2 Shielding Angle}

Radius of the protection zone $\mathrm{R}_{\mathrm{ro}}$ at the ground level for the air terminal of height $h[1]$;

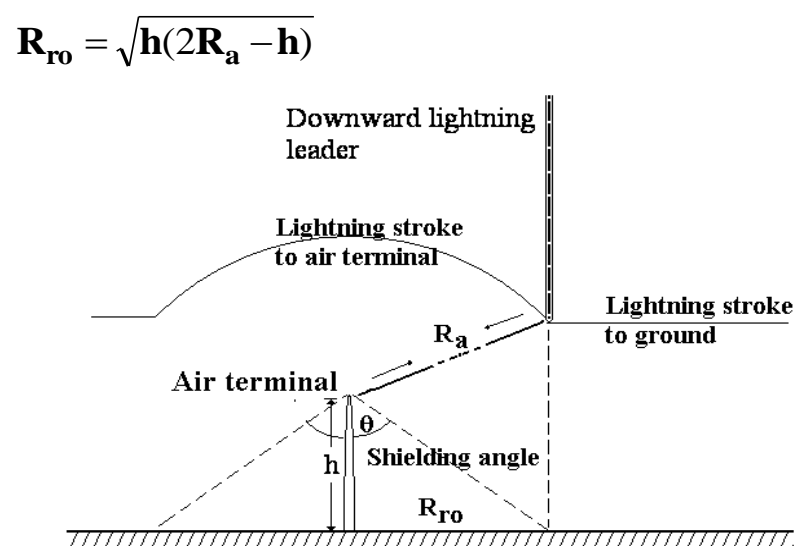

Fig. 6: Schematic arrangement of air terminal shielding angle

As shown in Fig. 6, the shielding angle $\left(\theta_{\text {sh }}\right)$ of the air terminal will be obtained from the following equation:

$$
\boldsymbol{\theta}_{\mathrm{sh}}=\tan ^{-1}\left(\mathbf{R}_{\mathrm{ro}} / \mathbf{h}\right)
$$

Figure 7 shows the effect of the vertical lightning leader current and the air terminal height on the shielding angle of the lightning rod. It shows that, the shielding angle increases as the vertical lightning leader current increases and as the air terminal height decreases.

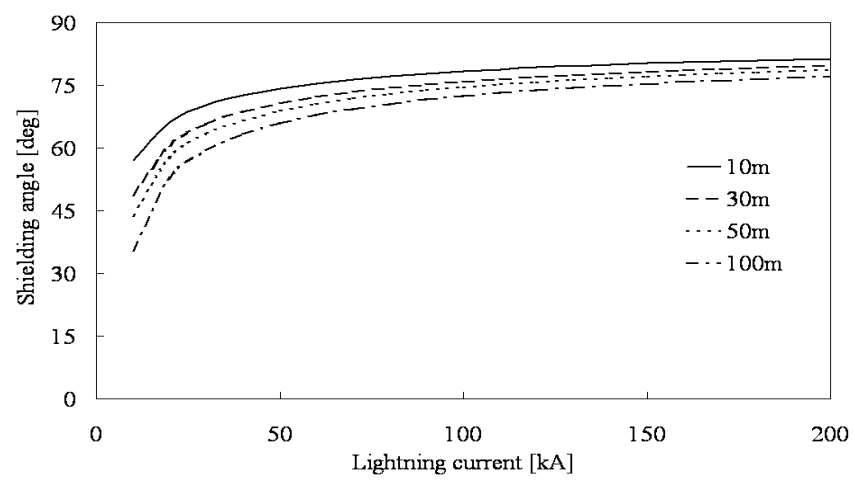

Fig. 7: Shielding angle for different vertical lightning leader currents and air terminal heights $(10,30,50,100 \mathrm{~m})$.

Figure 8 shows the effect of the lightning leader slope and the current on the shielding angle of the lightning rod. It shows that, the shielding angle increases as the lightning leader current increases and as the lightning leader becomes vertical. 


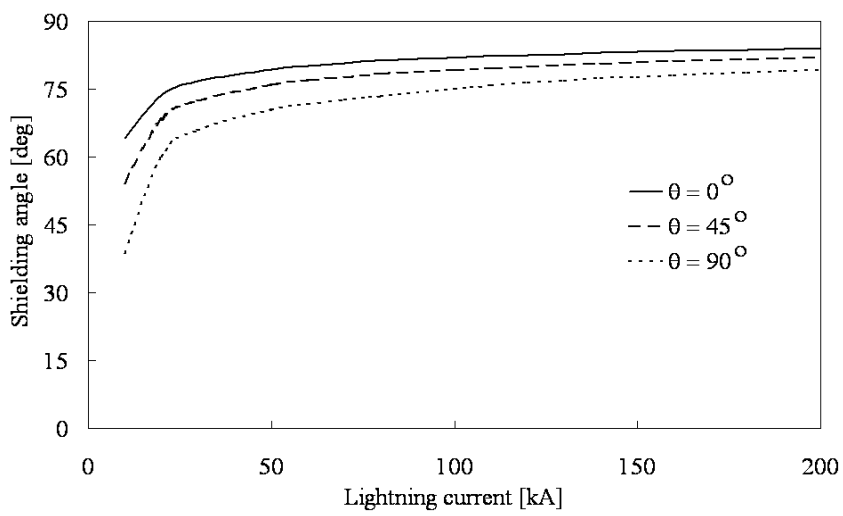

Fig. 8: Shielding angle for different lightning leader slopes $\left(0^{\circ}, 45^{\circ}\right.$ and $\left.90^{\circ}\right)$ and currents of air terminal of height $30 \mathrm{~m}$.

Figure 9 shows the shielding angle of median lightning current $31 \mathrm{kA}$ for different air terminal height for vertical and horizontal lightning leader as stream case. The shielding angel for the horizontal lightning leader is about 0.67 times that for the vertical lightning leader. There are many previous suggested values of the air terminal shielding angle such as $45^{\circ}$ or $60^{\circ}$ [10]. As shown in Fig. 8, the $60^{\circ}$ is suitable for the air terminal heights up to $100 \mathrm{~m}$ and the vertical lightning leader but is completely not suitable for the horizontal lightning leader. The $45^{\circ}$ shielding angle is suitable for all studied air terminal height and vertical lightning leader and the air terminal heights up to $35 \mathrm{~m}$ and the horizontal lightning leader. Also from Figs. 6, 7 and 9 the shielding angle of low lightning current is below $45^{\circ}$ and $60^{\circ}$. For all studied values the $30 \mathrm{o}$ shielding angle is recommended for vertical and horizontal lightning leaders and different air terminal heights.

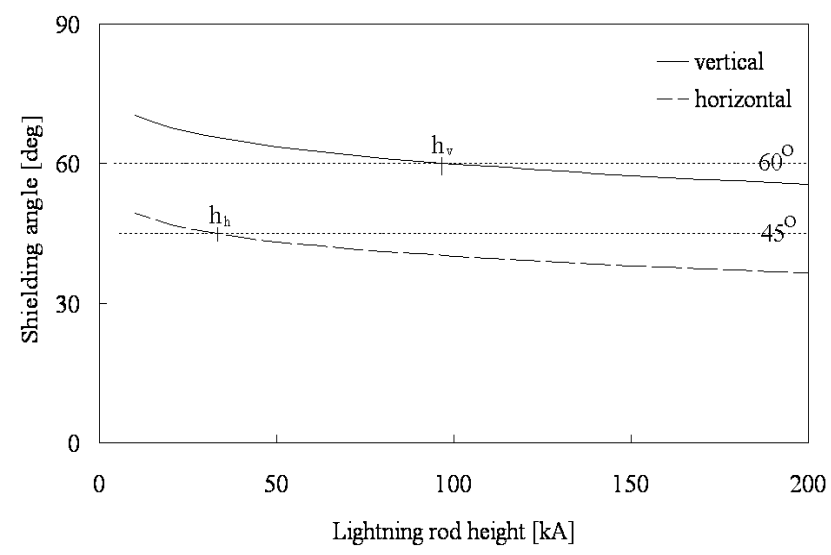

Fig. 9: Shielding angle for vertical and horizontal different lightning rod heights for median lightning current $31 \mathrm{kA}$

Figure 10 shows the effect of lightning leader slope on the lightning current where the shielding failure occurs for the previous recommended shielded angles $45^{\circ}$ and $60^{\circ}$. They are calculated for different air terminal heights $(10,30,50 \mathrm{~m})$. The 
lightning current where the shielding failure occurs for $45^{\circ}$ shielding design is no more than $20 \mathrm{kA}$ and less than that of $60^{\circ}$ shielding design $80 \mathrm{kA}$.

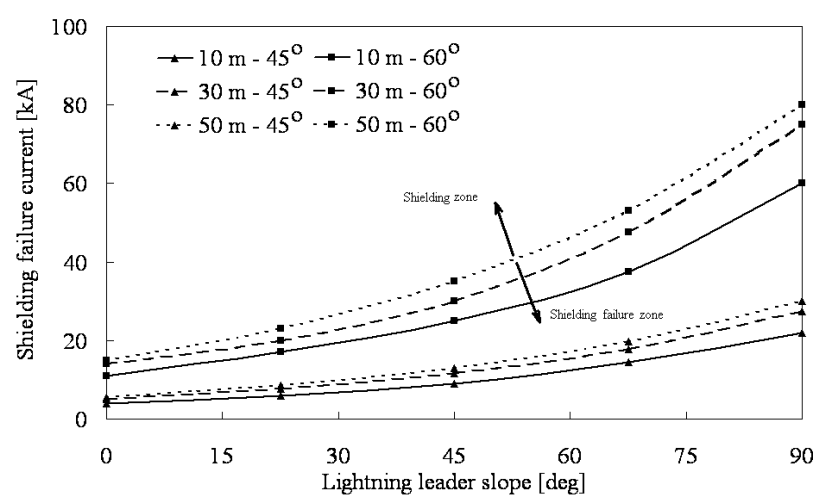

Fig. 10: Shielding angle for vertical and horizontal different air terminal heights for median lightning current $31 \mathrm{kA}$

\section{CONCLUSION}

One can obtain from the calculated results the following conclusions:

The attractive radius of the air terminal is dependent on air terminal height, lightning current for vertical and horizontal lightning leaders. The attractive radius of the air terminal is reduced seriously due to the horizontal lightning leader. The shielding angle of the air terminal shows a dependence on air terminal height, lightning leader current and slope. The shielding angle of the air terminal is reduced seriously due to the horizontal lightning leader. The lightning protection design by using lightning rods must consider the reduction of the shielding angle due to the lightning leader slope.

\section{REFERENCES}

[1] IEEE Std 998-1996," IEEE Guide for Direct Lightning Stroke Shielding of Substations", The Institute of Electrical and Electronics Engineers, Inc. New York USA, 1996

[2] Z. A. Hartono, I. Robiah," A Long term study on the performance of early streamer emission air terminals in a high keraunic region", 2003 Asia-Pacific Conference on Applied Electromagnetics (APACE 2003), pp. 146-150, July 2003.

[3] J. M. Tobias, "The basis of conventional lightning protection systems", IEEE Transaction on Industry Applications,vol. 40,no. 4, July/August 2004, pp. 958-962.

[4] Jun Takami, Shigemitsu Okabe ,"Characteristics of Direct Lightning Strokes to Phase Conductors of UHV Transmission Lines," IEEE Trans on Power Delivery,vol. 22,no. 1, January 2007, pp. 537-546.

[5] www.weatherquestions.com

[6] R. H. Golde, "Lightning" Vol. II: Lightning protection, Academic Press, New York, 1977.

[7] A. Mousa, and R.J. Wehling," A survey of industry practices regarding shielding of substations against direct lightning strokes", IEEE Transactions on Power Delivery, Vol. 8, No. 1, pp. 38-47, January 1993. 
[8] A. Mousa, and K. Srivastava," The implications of the electrogeometric model regarding effect of height of structure on the median amplitude of collected lightning strokes", IEEE Trans. On Power Delivery, vol. 4, no. 2, April 1989.

[9] A. C. Liew, "Assessment and design of lightning shielding systems", IEEE International Conference on Advances in Power System Control, Operation and Management, Hong Kong, pp. 791-796, November 1991.

[10] T. Shindo, and Y. Aihara, " A shielding theory for upward lightning”, IEEE Trans. on Power Delivery, vol. 8, no. 1, January 1993, pp. 318-324.

[11] M. Abdel-Salam, M. El-Mohandes, G. Berger and B. Senouci," Onset criterion of upward streamers from a Franklin rods", Journal of Electrostatics, no. 24, pp. 45-59, 1989

[12] A. J. Eriksson," Lightning and tall structures", Trans. South African IEE, vol.69, no.8, pp. 238-252, August !987.

[13] F. Rizk," Modeling of transmission line exposure to direct lightning strokes", IEEE Trans. on Power Delivery, vol. 5, no. 4, Nov. 1990, pp. 1983-1997.

[14] M. Nayel, Z. Jie, J. He, Z. Cai, Q. Wang,” Study different charges distribution of lightning leader strike horizontal conductor" 15th ISH, Ljubljana, Slovenia, August 27-31, 2007, paper T2-261.

[15] Lightning and Insulator Subcommittee of the T\&D Committee," Parameters of Lightning Strokes: A Review ",IEEE Transaction on Power Delivery, vol. 20, no.

1, pp. 346-358, January 2005.

[16] Adrian van den Bos, Parameter Estimation for Scientists and Engineers, A John Willey \& Sons, Inc, 2007

[17] B.Y. Lee, J.K.Park, S.H.Myung, S.W. Min, and E.S. Kim,” An Effective Modelling Method to Analyze Electric Field around Transmission Lines and Substations Using a Generalized Finite Line Charge", IEEE Transactions on Power Delivery, Vol. 12, No. 3, pp. 1143-1150, July 1997.

\section{APPENDIXES}

\section{I- Potential Coefficients for Simulation Downward Lightning Leader}

The potential coefficient $P_{n \ell}$ of simulation slant finite line charge of downward lightning leader calculated at a given any point of coordinates $\left(\mathrm{x}_{\mathrm{p}}, \mathrm{y}_{\mathrm{p}}, \mathrm{z}_{\mathrm{p}}\right)$ is [17]

$$
P_{n \ell}=\frac{1}{4 \pi \varepsilon_{0} E} \ln \left[\frac{F+2 E+\sqrt{E(E+F+G)}}{F+2 \sqrt{E G}}\right],
$$

where

$$
\begin{aligned}
& E=\sqrt{\left(x_{n \ell 2}-x_{n \ell 1}\right)^{2}+\left(y_{n \ell 2}-y_{n \ell 1}\right)^{2}+\left(z_{n \ell 2}-z_{n \ell 1}\right)^{2}} \\
& F=\sqrt[\begin{array}{l}
\left(x_{p}-x_{n \ell 1}\right)\left(x_{n \ell 2}-x_{n \ell 1}\right) \\
+\left(y_{p}-y_{n \ell 1}\right)\left(y_{n \ell 2}-y_{n \ell 1}\right) \\
+\left(z_{p}-z_{n \ell 1}\right)\left(z_{n \ell 2}-z_{n \ell 1}\right)
\end{array}]{G=\sqrt{\left(x_{p}-x_{n \ell 1}\right)^{2}+\left(y_{p}-y_{n \ell 1}\right)^{2}+\left(z_{p}-z_{n \ell 1}\right)^{2}}}
\end{aligned}
$$


and where $x_{n \ell 1}, y_{n \ell 1}, z_{n \ell 1}, x_{n \ell 2}, y_{n \ell 2}, z_{n \ell 2}$ are the coordinates of the beginning and end of the $n^{\text {th }}$ finite simulation line charge which has a charge density $\rho_{n}$.

\section{دراسة تأثير ميل الصاعقة على التحجيب للأقطاب مانعة الصواعق

$$
\text { كلية الهندسة - محد نامعة اسيوط }
$$ \\ Phone :+20(88)2411718_Email:m_a_niel@yahoo.com}

هذه المقالة تقوم بدراسة تأثير ميل مسار الصاعقة على زاوية التحجيب للاطراف الهوائية (موانع

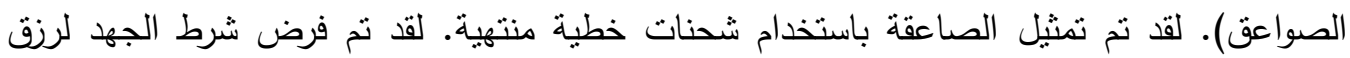
كعلامة لبدئ الصاعقة الصاعد الذى يعتبر شرط لضرب الصاعقة للطرف الهوائى. لقد نم حساب البعد

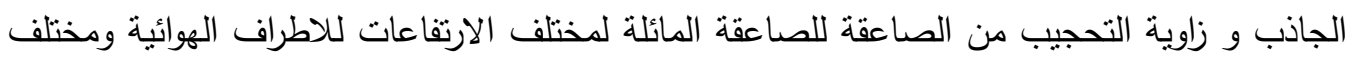

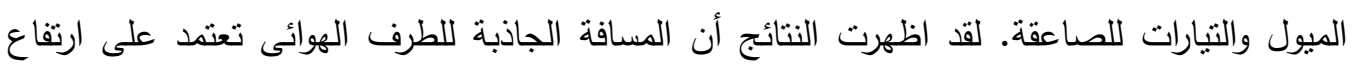

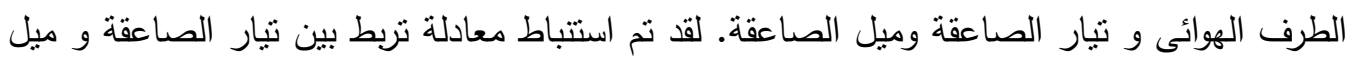
الصاعقة و المسافة الجاذبة للطرف الهوائى و ارتفاع الطرف الهوائى. ميل الصاعقة يؤدى الى تتاقص الهص زاوية التحجيب خاصة للصواعق ذات التبارات المنخفضة وللاطراف الهوائية المرتقعة. 